\title{
Post-cooling fever in post-cardiac arrest patients: post-cooling normothermia as part of target temperature management?
}

\author{
Cathy De Deyne \\ From Targeted Temperature Management (TTM 2014) \\ Berlin, Germany. 6-7 November 2014
}

Experimental studies support that fever after ischaemic brain injury may not only be a surrogate marker for severe cerebral ischaemia but may also deteriorate pre-existent cerebral ischaemic damage and should therefore be treated $[1,2]$. Neurological damage after cardiac arrest (CA) still determines the final outcome and post-CA critical care focuses on maximal neuroprotection, the application of therapeutic hypothermia (TH). Since the use of $\mathrm{TH}$, many reports have been published on the occurrence of fever post $\mathrm{TH}$ or so-called post-cooling fever (PCF). However, the incidence of post-CA fever without $\mathrm{TH}$ is similar, ranging from 20 to $78 \%$, suggesting that episodes of temperature $>38^{\circ} \mathrm{C}$ are likely to occur in all patients after $\mathrm{CA}$ irrespective of whether $\mathrm{TH}$ was administered.

Bro-Jeppesen and colleagues reported a higher 30-day mortality in patients with PCF (temperature $>38.5^{\circ} \mathrm{C}$ ) compared with patients without (36\% vs. $22 \%$ ) [3]. Likewise, 1-year unfavourable neurological outcome ( $43 \%$ vs. 27\%) was higher in patients with PCF compared with patients without. Maximum temperature and PCF duration were independent predictors of mortality. Their PCF incidence $(50.4 \%, 136 / 270)$ was high, probably explained by a longer observation period (36 hours). Leary and colleagues reported a PCF incidence of $41 \%$ (69/176) within 24 hours after rewarming [4], while Gebhardt and colleagues reported a $42 \%$ incidence $(141 / 336)$ within 48 hours after CA [5] (both defined PCF as temperature $>38^{\circ} \mathrm{C}$ ).

Most importantly, recent data suggest that the effect on mortality becomes significant only with $\mathrm{PCF}>39^{\circ} \mathrm{C}$ and a minimum duration of 7 hours. Similarly, Leary and colleagues did not find any effect of PCF on survival and neurological outcome, but a maximum temperature

Department of Anesthesiology and Critical Care Medicine, Ziekenhuis OostLimburg Genk, Belgium; Faculty of Medical Life Sciences, University Hasselt $\mathrm{UH}$, Hasselt, Belgium 
2. Baena RC, Busto R, Dietrich WD, Globus MY, Ginsberg MD, et al: Hyperthermia delayed by $24 \mathrm{~h}$ aggravates neuronal damage in rat hippocampus following global ischemia. Neurology 1997, 48(3):768-773.

3. Bro-Jeppesen J, Hassager C, Wanscher M, Soholm H, Thomsen JH, Lippert FK, et al: Post-hypothermia fever is associated with increased mortality after out-of-hospital cardiac arrest. Resuscitation 2013, 84(12):1734-1740.

4. Leary M, Grossestreuer AV, lannacone S, Gonzalez M, Shofer FS, Povey C, et al: Pyrexia and neurologic outcomes after therapeutic hypothermia for cardiac arrest. Resuscitation 2013, 84(8):1056-1064.

5. Gebhardt K, Guyette FX, Doshi AA, Callaway CW, Rittenberger JC, Post Cardiac Arrest Service, et al: Prevalence and effect of fever on outcome follwing resuscitation from cardiac arrest. Resuscitation 2013, 84(8):1062-1067.

6. Brugger $H$, Paal P: Does untreated post-cardiac-arrest fever counteract the benefit of therapeutic hypothermia? Resuscitation 2013, 84(12):1650-1651.

doi:10.1186/1471-227X-15-S1-A8

Cite this article as: De Deyne: Post-cooling fever in post-cardiac arrest patients: post-cooling normothermia as part of target temperature management? BMC Emergency Medicine 2015 15(Suppl 1):A8.

\section{Submit your next manuscript to BioMed Central} and take full advantage of:

- Convenient online submission

- Thorough peer review

- No space constraints or color figure charges

- Immediate publication on acceptance

- Inclusion in PubMed, CAS, Scopus and Google Scholar

- Research which is freely available for redistribution

Submit your manuscript at www.biomedcentral.com/submit 